\title{
Exploring Factors Faced by Teachers in Curriculum Implementation
}

\author{
Mutendwahothe Walter Lumadi \\ Department of Curriculum and Instructional Studies, College of Education, \\ University of South Africa, South Africa \\ Lumadmw@unisa.ac.za
}

Doi:10.5901/mjss.2014.v5n6p171

\begin{abstract}
This study explores factors faced by teachers in curriculum implementation in the North West and Limpopo Provinces. The theoretical framework that underpins this study is based on Herzberg's two-factor theory which is also known as motivationhygiene theory. A mixed methodology of qualitative and quantitative was used. Semi-structured interviews and questionnaires were employed as the research instruments for data collection, with 160 teachers from the five districts of the two provinces. Findings revealed that the curriculum transformation process, contributed to the dissatisfaction of teachers regarding the implementation of the new curriculum (CAPS). Recommendations were formulated by empowering teachers, for the effective implementation of the school curriculum.
\end{abstract}

Keywords: curriculum implementation; CAPS; curriculum transformation; Herzberg's two factor theory; North West; Limpopo province.

\section{Introduction}

The presence of a sense of community among qualified teachers and students has long been held by education researchers to be one of the most important indicators of successful schools (Carl, 2002). Based on this perspective, it can be safely said that a rapid turnover in teachers drives various stakeholders frantic in view of its negative repercussions. It is disruptive to the quality of school life and the students' performance. University graduates are absorbed into the teaching profession having invested several years of their lives and large amounts of money to realise a dream of making a difference in the lives of school students. However, it is counterproductive, to say the least, when they are thrown into the deep end, they fail to cope with the appalling working conditions and eventually quit. This deluge of teachers' turnover is over and above the thousands of teachers who retire annually.

\section{Literature Review and Theoretical Framework}

Frederick Herzberg's motivation-hygiene theory (1964), which is also regarded as a two-factor theory underpins this study. It postulates that there are certain factors in the workplace that lead to job satisfaction, while a separate set of factors cause dissatisfaction. This theory was developed by Herzberg, a psychologist who believed that job satisfaction and job dissatisfaction act independently of each other. It is imperative, to note that, the relevance of the theory in this study shows that, employees who are happy at work perform, while those who are unhappy are problematic to job production. This was very different to the common belief that the issues of satisfaction and dissatisfaction are simply opposing reactions to the same circumstances. Instead, dissatisfaction is caused by poor assessments of job-related factors. Herzberg called the satisfiers motivators and the dis-satisfiers hygiene factors - using the term hygiene in the sense that they are considered maintenance factors, necessary to avoid dissatisfaction but by themselves they do not provide satisfaction.

Motivators actually motivate an individual. They find their root within the job itself. Hygiene factors do not have any motivational value when present, but do have a de-motivational value if not present. These factors are extrinsic to the work itself. A doctoral study by Boord (2010) which focussed on the use and application of Herzberg's motivation-hygiene theory to predict job satisfaction in teaching improvement and professional development was conducted. Findings of Boord's study revealed that there was a strong relationship between independent variables and the dependent variable, overall job satisfaction.

Moreover, another study by Ramdan and Naicker (2011) revealed that there should be a strong bond between the Department of Education as the employer and educators as employees, whereby the Department of Education should implement motivation strategies to enhance educator work performance. Although Herzberg's theory focuses on both the 
satisfiers and dis-satisfiers, it is imperative to note that the motivation-hygiene theory will be universally accepted in this study, as an appropriate explanation for job dissatisfaction. This theory has critical ramifications for traditional approaches to attitudes of teachers in the workplace, and how to influence them. Herzberg's theory is much relevant in this study as it focuses on the negative side of teachers who are unproductive, and in the process, result in high turnover. Teachers who experience low job satisfaction often exit the profession of teaching entirely exacerbating the attrition problem.

\section{Method}

\subsection{Ethical Considerations}

Before I could begin with the study, I registered the research project and permission was granted by the Quality Assurance unit of the North West and Limpopo Department of Education.

\subsection{Research Paradigm and Design of data collection instruments}

A positivist-interpretive research paradigm foregrounded this study. A structured questionnaire, designed on a four point Likert Scale (Strongly Disagree $=S D$, Disagree $=D$, Agree $=A$ and Strongly Agree $=S A$ and a semi-structured interviews were employed to collect data for this study. A reliability test was computed, Cronbach alpha ( $p>.7)$, to test the reliability of the questionnaire, which revealed an average of .83.

The study used purposive sampling in thirty schools, five from each of the four districts in the North West (NW) and five from Limpopo province in Vhembe district which were selected as sites for the study. The participants from secondary schools were randomly sampled. Despite the intuitive appeal of Herzberg's two-factor theory, its only solid support comes from a qualitative methodology called "critical incident technique" (CIT). The problem with CIT is that it allows employees to take credit for their own achievements, while blaming failure on external factors. For the purpose of this study, the mixed method employed was suitable to achieve the outcomes of this particular study. On the other hand similar studies which were conducted based on Herzberg's motivation hygiene theory revealed different outcomes (Boord, 2010; Shezi, 2005).

\subsection{Participants and Demarcation}

The schools (urban, rural and farms) were from the following five districts municipalities; Bojanala Platinum (in Rustenberg), Ngaka Modiri Molema (in Mafikeng), Dr Kenneth Kaunda (in Tlokwe formally known as Potchefstroom), Dr Ruth Segomotsi Mompati (in Greater Taung) and Vhembe in Thohoyandou. With the assistance from the provincial (see figure, 1 of the NW province map), Department of Education, the schools were selected on the basis of their very high staff turnover. One hundred and sixty $(n=160)$ teachers who completed the questionnaires were also interviewed, through face-to-face and group interviews from each education district (see summary of biographical data in Table 1).

Table 1: Summary of biographical data

\begin{tabular}{|c|c|c|c|}
\hline \multirow[t]{2}{*}{ Information of participants } & \multicolumn{3}{|c|}{ Summary of responses } \\
\hline & $\mathrm{F}$ & $\%$ & $\%$ \\
\hline \multicolumn{3}{|c|}{ Gender $(n=160)$} & 160 \\
\hline Male & 75 & 47 & \\
\hline Female & 85 & 53 & \\
\hline \multicolumn{3}{|c|}{ Age $(n=160)$} & \\
\hline $27-34$ years & 67 & 42 & \\
\hline $35-39$ years & 34 & 21 & \\
\hline $40+$ years & 59 & 37 & \\
\hline \multicolumn{3}{|c|}{ Teaching Experience } & \\
\hline $1-5$ years & 21 & 13 & \\
\hline $6-10$ years & 69 & 44 & \\
\hline $11-15$ years & 35 & 21 & \\
\hline $16-20$ years & 16 & 10 & \\
\hline $21+$ years & 19 & 12 & \\
\hline
\end{tabular}




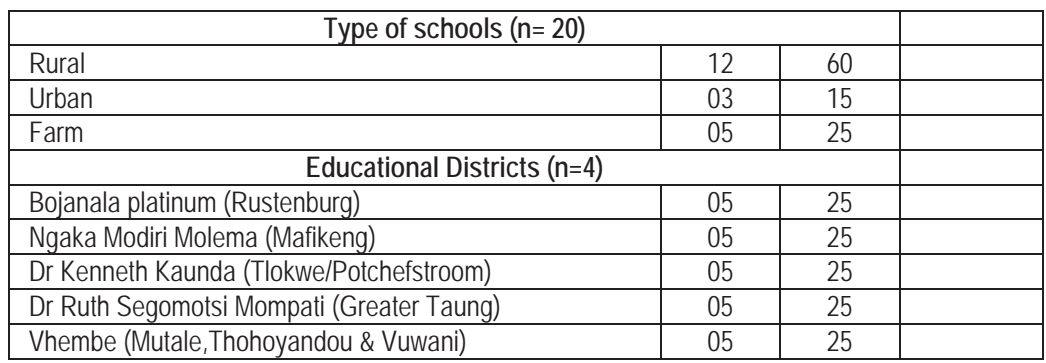

Both the questionnaires and interviews addressed challenges faced by teachers regarding curriculum implementation in the provinces. The following main research question was posed for the purpose of conducting the study:

* What are the key challenges faced by teachers regarding curriculum implementation in the North West and Limpopo Provinces?

The following sub-research questions were also formulated to achieve the objectives of the study;

- What are the external factors that impact negatively on teachers in curriculum implementation? and

- What are the internal factors that impact negatively on teachers in curriculum implementation?

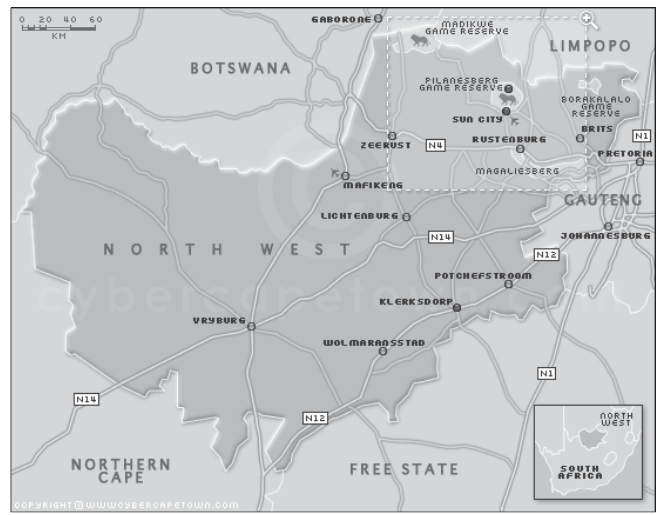

Figure 1: Map of the North West Province

\section{Findings and Discussion}

Emanating from the responses on the questionnaires and interviews regarding various factors that are of importance in teaching and learning are discussed regarding the delivery of curriculum implementation in their respective classrooms (see figure 2). Responses to the following question are identified in figure (2).

* What are the external factors that impact negatively on teachers in curriculum implementation?

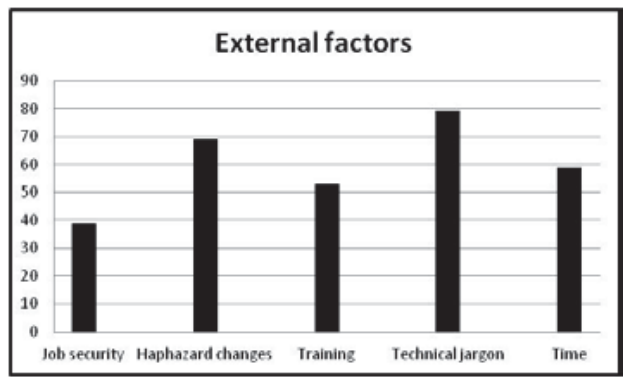

Figure 2: External factors impacting on teachers in curriculum implementation 
It is imperative to note that the five factors listed in figure 2 were considered by the teachers as important influences on their ability to implement the curriculum effectively.

\subsection{Job security}

Job security is a tangible variable sought by both principals and teachers whilst employed by the Department of Basic Education. In the above figure (2), 39\% of the respondents were dissatisfied with job security in South African schools. Job security has become more significant during the economic meltdown, with hiring freezes becoming everyday news. Teachers as government employees serve a vital function that cannot be automated or off shored and certainly not underfunded. Yet presently teaching jobs in South Africa are less secure than at any time since the economic depression, even as we are officially climbing out of the present recession. In fact, temporary appointments in many Eastern Cape districts are greater now than during the worst of the recession. In 2011, 6000 teachers were absorbed by different schools in the province on short-term contracts, resulting in job insecurity, the loss of potential holiday pay and inability for some to take out car and home loans. Of those on contracts, $90 \%$ said having to reapply for positions had a negative effect on their teaching. It is appalling to see lack of tenure as the most important issue they faced. Moreover, teachers with leadership positions such as heads of department, deputy principals and principals felt their positions were threatened.

\subsection{Haphazard changes}

In terms of the results presented in the above figure (2), sixty nine percent (69\%) of the teachers were concerned with the sporadic changes in the curriculum which rendered them incompetent. Curriculum change in any country is an on-going process which does not happen overnight. It demands planning, perseverance and dedication from teachers. A curriculum plan must be developed according to the specific character of a school by the whole staff.

\subsection{Training}

Fifty three (53\%) of the teachers complained that they did not receive enough in-service training. Furthermore, respondents indicated that training plays an important role on the delivery of quality of teaching and learning through curriculum implementation in their respective schools. Most teachers in rural areas received training for three to five days. This was an inferior type of training and some teachers had to resign. It became a challenge to Grade 12 students who were left without teachers. This had a bearing to mathematics and science subjects. Mathematics is sequential in nature. That means that one concept, knowledge or skill builds on the top of another. While this is true in most if not all subjects it is more apparent in Math. Students who have not mastered a preceding skill have difficulty in learning new work. Mathematics is also an exact subject. All the other elementary and secondary school subjects are not as exact. Many students have trouble with the exactness of mathematics. This period of training did not suffice at all. In actual fact, teachers felt it would have sufficed if their training was detailed and also prolonged to a period of a year prior implementation. Although it was raised with government officials, their response was focused on budgetary constraints.

\subsection{Technical jargon}

Seventy nine percent (79\%) of the South African curriculum that emerged from the process was described in terms of outcomes, hence the concept of Outcomes-Based Education characterised by abstruse technical jargon and a host of new concepts for schools and teachers to digest. Teachers felt that there was too much jargon in the curriculum such as critical outcomes, specific outcomes, cross field outcomes and the other. The participants further reported that the changes Outcomes-Based Education, Revised National Curriculum Statement, National Curriculum Statement and now Curriculum Assessment Policy Statements had their own jargon which was cumbersome. The mastery of the technical jargon was taxing on teachers and it affected their daily preparation in mathematics and science. "Cass" for continuous assessment is currently problematic to teachers in their implementation of curriculum.

\subsection{Time}

Teachers were of the opinion that they did not have enough time to implement the curriculum effectively. Sixty percent (60) of the participants ( $n=)$ identified the time factor as a tedious challenge to both teachers and curriculum developers. 
The new curriculum presented the teachers with awkward deadlines which they knew were impossible to keep in view of their demanding workload and the process was constantly constrained by severe time pressures and overly optimistic planning. Teachers who had morning and afternoon studies did not have time for supervision of morning and afternoon studies. It was in these studies were most students were helped with difficult issues on mathematics such as algorithms and chemistry concepts. Mathematics is made up of several themes, including abstract algebra, calculus, statistics, geometry and complex analysis. The four thinking standards that are involved in mathematics are connection, communication, problem solving and reasoning.

Teachers' responses to the following question are highlighted in Figure 3.

* What kind of internal factors impact negatively on teachers in curriculum implementation?

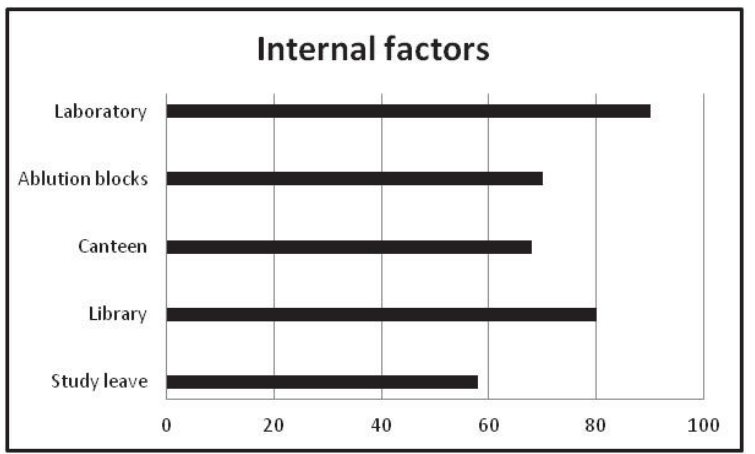

Figure 3: Internal factors impacting on teachers in curriculum implementation

Based on the results presented in Figure 3, teachers indicated that the following internal factors such as laboratories for mathematics and science (90\%), libraries (80\%), ablution blocks (70\%), canteen (68\%) and study leave (58\%) play a significant role on the delivery of quality of teaching and learning through curriculum implementation in their respective schools.

Fifty eight percent (58\%) of the participants reported that academic leave is no longer granted to teachers who want to further their studies on full time basis. The Ministry of Education's current statistics show that $40 \%$ of male teachers and $60 \%$ of female teachers struggle to meet the basic requirements of a Category $C(M+3)$ or a three-year tertiary qualification (Beane, 2005 \& Bhengu, 1997).

Responses to the following main research question in the study are highlighted in figure 4.

* What are the key challenges faced by teachers regarding curriculum implementation in the North West and Limpopo Provinces?

Figure 4 depicted the challenges faced by teachers which strongly agreed to agree that the factors; curriculum transformation (83.5\%) and resources and facilities (67\%) have been significantly impacted on the quality of curriculum implementation in the province. A detailed discussion follows under results and discussion of qualitative method.

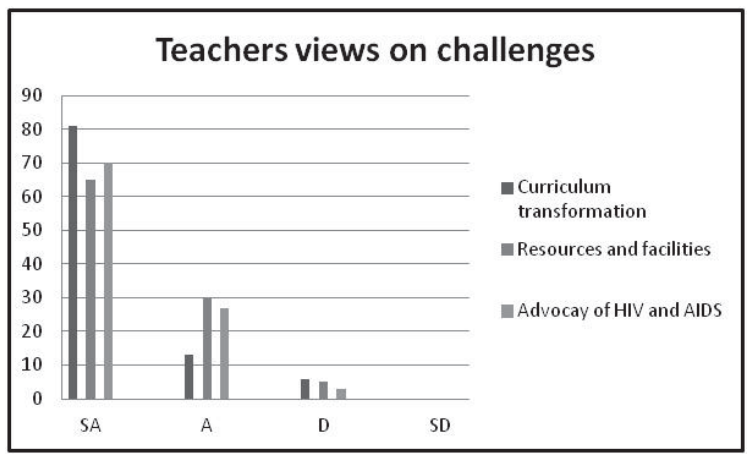

Figure 4: Teachers' views on challenges they face 
Emanating from the analysis of data (interviews), what is noteworthy is the close similarity in the findings across 160 different participants in the different districts of the NW and Limpopo.

\subsection{Theme 1: Curriculum Transformation}

Employees tend to enjoy working for a company that allows them to use their personalities and abilities to create a fun work environment. Many companies are beginning to employ methods to give employees more responsibility and control and to involve them more in their work, which serves to motivate them to higher levels of productivity and quality (Herzberg,1964). There has been a rapid expansion of knowledge and a lot of innovations in education. South Africa, like any other country in the world, realised that there was a need to examine the curricula of all their programmes. It was realised that the only way to meet the needs of students was to adjust the curricula. In 1996, South African inaugurated a process to transform the country's curriculum, particularly in terms of its vision. The country had to be seen delivering on its education promises, and thus needed a new curriculum to be published and at least partially implemented before the 1999 elections (Sieborger, 1998).

Roux (2009:18) argues that transformative curriculum development, as a means of reducing the discrepancy between curriculum developments and the changing needs of curriculum stakeholders, seemed to be one way of dealing with transformation in teacher education. It is imperative that curriculum developers have to take precautionary measures so that they do not undermine the system with too much red tape. A relevant curriculum is learner-centred. Learnercentred education theory, like all social theories, has high ideals namely, an education revolution that will make each and every child a successful learner (Horn, 2009:511-512). Developing a curriculum that meets the needs of students is a complex process that rarely follows a prescribed pattern because a curriculum is a dynamic process that needs to be reviewed constantly (Finch \& Crunkilton, 2004).

Over the course of 1996 and 1997, various curriculum committees representing a range of stakeholders were charged with the task of giving birth to the new curriculum (Sieborger, 1998). Curriculum 2005 covered Grades 1 - 9. Subjects were subsumed into eight learning areas. The new curriculum was duly implemented in stages in 1998 . The teaching of skills and concepts was compulsory. By implication, a repertoire of teaching and learning strategies such as discussion, debate and questioning were of paramount importance (Hoadely \& Jansen, 2009).

The introduction of the $3 R s$ policy, namely, rationalisation, retrenchment and redeployment was a thorn in the flesh of many teachers. Teachers were scattered across the province like sheep without a shepherd. Interviewee $X$ from Bojanala Platinum related the following story:

"Originally I am from Rustenburg which is about 400kms single trip from Pudumong (Under Dr Ruth Segomotsi Mompati). Although I love my family I cannot afford to be home every weekend. I only see my family at least once in a month. This has serious financial implications on my side. I rent a room in someone's house. I have a maid who cooks and looks after my laundry. I have to bear the costs for all this unnecessary expenditure. We as teachers are separated from our families and only managed to go home at least once a month."

Emanating from the $\mathrm{R} \& \mathrm{R}$ policy ${ }^{1}$ and interviewees responses, it is evident that South African teachers were redeployed to various districts away from their homes which have negative repercussions on curriculum transformation. This has serious financial implications on the daily mobility commuting between home and work. Furthermore, some of the teachers indicated that they had to lodge in the houses closer to their newly appointed schools. This on its own resulted in marital problems because some teachers ended up practising polygamy. Interviewee $Y$ from Tlokwe district remarked on the issues of relationship between teachers and minors:

"The code of teachers restricts us from having affairs with students. It is embarrassing to us as professionals when some of the teachers have affairs with school children. It was reported in one of the meetings that some of the teachers' succumbed to the temptation of using students as their concubines. It was further alleged that in some schools, teenagers' pregnancies is rife and we are the ones to blame for all this unacceptable behaviour."

The children of single parents were left behind on their own in some cases. These children whose parents were redeployed to other districts and provinces could no longer cope with their academic work. They were failing Grades whilst those who passed were often borderline cases. The results for most grade 12 students were not good enough to meet university admission requirements. Some parents did not want to compromise the safety of their children whilst they

${ }^{1}$ Rationalisation and Redeployment 
were redeployed to other districts. Although some of them appointed maids to stay behind looking after their children, this did not pay dividends because there were unforeseen teenage pregnancies. Many families were broken in the process of curriculum transformation, as is evident by the number of divorcees who were casualties of this factor. In 2000, the Minister of Education, appointed a committee to review the structure and design of Curriculum 2005. The committee further looked at the teacher training and development, provincial support to teachers in schools and the implementation of time frames. The Revised National Curriculum Statement (RNCS) was introduced followed by the National Curriculum Statement. The RNCS streamlined and strengthened Curriculum 2005 which was committed to OBE (Fullan \& Pomfret, 2005).

A lot of teachers had mixed feelings about curriculum change. They did not welcome this change because it brought a lot of fears that needed to be allayed. There was a fear that as experts their roles were not clear in the new curriculum. Some of the teachers still have not yet clearly understood the new curriculum. Some have said that teaching was no longer rewarding but time consuming. The six days training they received from workshops was insufficient as it was done haphazardly.

Teachers felt that too much emphasis has been put on self-directed learning overriding other learning methods (Goody \& Brophy, 2003). Others were of the opinion that since planning and implementation were taking place concurrently it has delayed the process. Other teachers felt that the students are overloaded with work. There was fear that the new curriculum required more human resource than the traditional curriculum. Some teachers felt that the change was introduced hurriedly with limited departmental involvement and that was the reason some experienced difficulty simply in implementing the new curriculum. As for primary school teachers, they maintained that curriculum transformation demanded a lot of administration from them. As a new democratic country, South Africa has a vision, of promoting the Culture of Teaching and Learning Service. This can only be achieved through having a dynamic and vibrant curriculum that involves the teachers and students (Ntshingila-Khosa, 1996). It was through the participatory approach that a wide range of stakeholders were involved successfully in the change process. This has led to an appreciation of the advantages of change, the enlisting of collective support, team work, seeking the collaborators and enlisting leadership at all levels. The major changes that have come about through the review of the curriculum include problem-centred design, student-centred design and thematic-centred design. The new curriculum offers an opportunity for the students to take charge of their learning (Darling-Hammond, 1997)). They are not supposed to rely solely on teachers because the approach is not of a subject-centred design. Students acquire expertise in looking for their own learning resources and knowledge.

\section{Recommendations}

It is imperative to note that recommendations are formulated to curb teachers leaving the profession regarding the following:

\section{* Curriculum Transformation}

Teachers must be fully involved in all curriculum transformation processes. All stakeholders such as teachers, Unions, School Management Teams, School Governing Bodies must be included in the decision-making process of curriculum transformation. The inputs of all stakeholders should be accommodated through the process of designing any curriculum which must be relevant in the context of the community.

\section{Conclusion}

The study explored challenges faced by teachers regarding curriculum implementation in the North West and Limpopo Provinces. It became evident from the study that Herzberg' theory is universally accepted as an appropriate explanation of job dissatisfaction which resulted in teachers' exodus. Herzberg knew that job satisfaction is important for both the employee and the employer. To get the most of an employee an employer should make sure they use a two pronged approach to employee satisfaction.

Findings revealed that the curriculum transformation process, contributed to the dissatisfaction of teachers regarding the implementation of the new curriculum. The exit of thousands of teachers, from their profession on a daily basis, and their movement to greener pastures is a daunting task. It has a bearing on the students, who lose the value of being taught by experienced teachers, and to the schools, the Ministry of Education and the country which must recruit and train their replacements. As long as the Department of Basic Education does not intervene, the unenviable situation will continue to deteriorate. 


\section{References}

Beane JA 2005. Curriculum planning and development. Boston: Allyn and Bacon.

Bengu SME 1997. Address from the steps of parliament on the occasion of the launch of Curriculum 2005. Cape Town: Government Printer.

Boord A 2010. "Analysis of adjunct faculty at Des Moines Area Community

College: Use and application of Herzberg's motivation-hygiene theory to predict job satisfaction in teaching improvement and professional development" (2010). Theses and Dissertations. Paper 11739. http://lib.dr.iastate.edu/etd/11739. Accessed on 22 May 2012.

Carl AE 2002. Teacher Empowerment through Curriculum Development (2nd ed). Lansdowne: Juta and Company.

Darling-Hammond L 1997. The right to learn. San Fransisco: Jossey-Bass.

Department of Education 1996. Education White Paper 2: The Organisation, Governance and Funding of Schools. Pretoria: Government Printer.

Finch CR \& Crunkilton JR 2004. Curriculum development in vocational and technical education. Boston: Allyn and Bacon.

Fullan M \& Pomfret A 2005. Review of research on curriculum implementation. Toronto: The Ontario Institute for Studies in Education. Goody TL \& Brophy J 2003. Looking in classrooms. New York: Harper and Row.

Herzberg F 1964. The Motivation-Hygiene Concept and Problems of Manpower", Personnel Administration, 3-7.

Hoadley U \& Jansen J 2009. Curriculum. Organising knowledge for the classroom. Cape Town: Goodwood.

Horn, I 2009. Learner-centeredness: an analytical critique. South African Journal of Education, 29: 511-525.

Ntshingila-Khosa R 1996. Teachers' pedagogical practices: Studies in Soweto classrooms. Durban: The improving Education Quality Project.

Ramdan S and Naicker I 2011. Factors that influence educator work performance in four primary schools in Kwa Zulu Natal. Thesis (M.Ed.)-University of KwaZulu-Natal: Durban.

Roux C 2009. Holistic curriculum development: tutoring as a support process. South African Journal of Education, 29:17-32.

Shezi SG 2005. An evaluative study of the principal's leadership role in facilitating participative management. Masters Degree submitted in the Department of Educational Planning and Administration. Richards Bay: University of Zululand.

Sieborger R 1998. How the outcomes came out. Cape Town: Juta and Company. 